\title{
Effects of Peripherally Acting Opioid Ligands on Central Opioid Receptors and $\beta$-Endorphin Release in Stressed Rats
}

\author{
Sergey K. Sudakov*, Valentina G. Bashkatova, Tatiyana V. Proskuriakova, Alexey E. Umriukhin \\ P. K. Anokhin Research Institute of Normal Physiology, RAMS, Moscow, Russia \\ Email: ${ }^{*}$ s-sudakov@nphys.ru
}

Received November 18, 2011; revised January 22, 2012; accepted February 22, 2012

\begin{abstract}
Using the radioreceptor binding assay, $\mu$-opioid receptor (MOR) affinity in the midbrain of stressed rats was higher than in naive controls. MOR density in the rat frontal cortex was reduced after stress. Intragastric administration of the MOR antagonist naloxone methiodide was followed by an increase in the number of MORs in the frontal cortex. However, the MOR agonist loperamide significantly decreased the density of MORs in the frontal cortex and midbrain of naive animals. Loperamide and naloxone methiodide were shown to prevent an increase in MOR affinity and a decrease in MOR density in the midbrain of rats after restraint stress. The restraint stress was accompanied by an increase in the release of $\beta$-endorphin (BE) in the ventral tegmental area (VTA) of control rats. After administration, loperamide slightly decreased the release of $\mathrm{BE}$, naloxone methiodide significantly increased the release of $\mathrm{BE}$ in the cingulate cortex (CC) of untreated animals, while drugs had no effect on the release of BE in the VTA. The drugs significantly increased the extracellular level of $\mathrm{BE}$ in the $\mathrm{CC}$ of stressed animals. Loperamide abolished the increase in the stress-induced release of BE in the VTA. By contrast, naloxone methiodide significantly increased the release of BE in the VTA of stressed rats. Our data indicated that activation of peripheral MORs induces depression of the central part of the $\mu$-opioid system, but suppression of peripheral MOR activity induces activation of the central $\mu$-opioid system, the interaction of which can be modulated by stress.
\end{abstract}

Keywords: Peripheral Opioid Receptors; Emotional Stress; $\beta$-Endorphin; Microdialysis; Radioligand Binding; Density of $\mu$-Opioid Receptors

\section{Introduction}

An important contribution of endogenous opioid peptide systems to the mechanisms of emotional behaviour has been supported by numerous studies [1-4]. It has been suggested that the $\mu$-opioid receptor (MOR) may exert stress-specific regulation of amygdalar output circuits [5]. Morphine and opiates are known to exert stress-protective effects, probably through interactions with the GABAergic system [6-8]. An increased number of MORs was found after acute restraint stress as estimated by the use of $3 \mathrm{H}$-dihydromorphine binding or $3 \mathrm{H}$-naloxone binding [9]. There has been convincing evidence that the $\mu$-opioid system, implicated in responses to stress, is distributed in different brain regions [10]. It has been established that the level of one of the most important endogenous opioid peptides, $\beta$-endorphin (BE), in the cerebral cortex of rats significantly increases during emotional stress [11].

It is well known that the structure of opioid receptors

${ }^{*}$ Corresponding author.
(OR) and endogenous opioid peptides in the CNS and in the periphery is identical, but the central and peripheral functions of endogenous opioid systems are considered different because the blood-brain barrier (BBB) generally prevents the entry of peptides into the brain [12]. We hypothesized that the central and peripheral components of the endogenous opioid system function and interact closely with each other. Data supporting this hypothesis has shown, for example, that intraperitoneal injection of the MOR agonist loperamide, which does not penetrate the BBB effectively, reversed thermal hyperalgesia [13]. Our previous work showed that peripheral administration of the MOR antagonist naloxone methiodide produced central analgesia and an inhibition of the morphine withdrawal syndrome in rats. The peripherally restricted MOR agonist loperamide induced opposite effects [14]. Our pilot study showed, that the release of $\mathrm{BE}$ in the brain cortex of non-stressed rats was elevated after peripheral naloxone methiodide administration [15]. Based on these results, we suggested that activation of the peripheral opioid receptors may inhibit the central opioid system, 
whereas peripheral inhibition may activate central opioid mechanisms [16].

However, recently we found that both loperamide and naloxone methiodide induced anxiolytic, antistress effects in the elevated plus maze (EPM) test [17]. Hence, evaluating the specific features of relationships between the peripheral and central $\mu$-opioid systems under stress conditions is of interest. Our work was designed to study the effects of peripheral treatment with loperamide and naloxone methiodide on the characteristics of MOR in the cerebral cortex and midbrain of stressed rats. Our data suggested that both compounds do not cross BBB effectively, which is consistent with previous reports $[12,18]$. Moreover, we evaluated the influence of these agents on the release of $\mathrm{BE}$ in the cingulate cortex (CC) and in the ventral tegmental area (VTA) of the midbrain in rats.

\section{Materials and Methods}

\subsection{Animals}

Experiments were performed on male Wistar rats obtained from the Stolbovaja nursery (Russian Academy of Medical Sciences). The animals (basal weight 180 - $200 \mathrm{~g}$ ) were housed in cages (4 per cage) under a 12:12-h light-dark cycle with free access to food and water. The study was conducted at 12 - 5 p.m. Restraint stress was induced using 1-h immobilization of the rat on a platform. The experiment was conducted in accordance with the "Rules of Studies on Experimental Animals" (approved by the Ethics Committee of the P. K. Anokhin Institute of Normal Physiology; protocol No. 1, 3.09.2005), the requirements of the World Society for the Protection of Animals (WSPA), and the European Convention for the Protection of Experimental Animals.

\subsection{Radioreceptor Analysis of MOR in the Cortex and the Midbrain of Rats}

The $K_{d}$ and $B_{\max }$ parameters of binding to $\mu$-opioid recaptors were determined by radioreceptor analysis in midbrain and frontal cortex of control and stressed rats 30 min after administration of water or loperamide or methylnaloxone. $\left[{ }^{3} \mathrm{H}, \mathrm{D}\right.$-Ala ${ }^{2}, N$-Me-Phe ${ }^{4}$, Gly ${ }^{5}$-ol] enkephalin $(67 \mathrm{Ci} / \mathrm{mmol}$, Amersham) was used as the ligand for the MORs.

The corresponding brain area was homogenized at $4^{\circ} \mathrm{C}$ in $25 \mathrm{ml}$ of $50 \mathrm{mM}$ Tris-HCl buffer (pH 7.7) with a Douncetype homogenizer. The suspension was centrifuged three times at $30,000 \mathrm{~g}$ for $15 \mathrm{~min}$ at $4^{\circ} \mathrm{C}$. The supernatant was removed, and the pellet was resuspended at $25^{\circ} \mathrm{C}$ in 25 $\mathrm{ml}$ of $50 \mathrm{mM}$ Tris-HCl buffer (pH 7.7), incubated for 40 $\mathrm{min}$ at $37^{\circ} \mathrm{C}$ and then centrifuged at $30,000 \mathrm{~g}$ for $15 \mathrm{~min}$ at $4^{\circ} \mathrm{C}$. The pellet was resuspended at $25^{\circ} \mathrm{C}$ in $25 \mathrm{ml}$ of $50 \mathrm{mM}$ Tris- $\mathrm{HCl}$ buffer $(\mathrm{pH} 7.7)$ to get the final protein concentration of $0.4-0.8 \mathrm{mg} / \mathrm{ml}$.

The experiments on competitive radioreceptor analysis were carried out with the following reaction mixture $(0.5$ $\mathrm{ml}$ total volume): $50 \mathrm{mM}$ Tris- $\mathrm{HCl}$ buffer (pH 7.4, $200 \mu \mathrm{l}$, $\left.25^{\circ} \mathrm{C}\right)$, bacitracin solution $(50 \mu \mathrm{l}, 50 \mu \mathrm{g} / \mathrm{ml})$, the $3 \mathrm{H}$-labeled ligand $(50 \mu \mathrm{l}, 4 \mathrm{nM})$ and a suspension of membrane protein with a final concentration of 0.4 to $0.8 \mathrm{mg} / \mathrm{ml}$.

\subsection{Determination of $\beta$-Endorphin in the Cingulate Cortex and Ventral Tegmental Area}

Microdialysis probes (2 mm length, $20 \mathrm{kD}$ cut off value, CMA 12, CMA/Microdialysis AB, Stockholm, Sweden) were surgically implanted into the $\mathrm{CC}$ according to Paxinos and Watson [19]: $1.6 \mathrm{~mm}$ anterior and $1.8 \mathrm{~mm}$ lateral to bregma and $2.2 \mathrm{~mm}$ ventral to the surface of the skull with an angle of $20^{\circ}$ ). Coordinates of the VTA were 6.0 $\mathrm{mm}$ posterior and $1.8 \mathrm{~mm}$ lateral to bregma and $7.3 \mathrm{~mm}$ ventral to the surface of the skull. Artificial cerebrospinal fluid (aCSF) was pumped continuously $(1 \mu \mathrm{l} / \mathrm{min})$ through the dialysis probe using a microinjection pump (Stoelting Co., Wood Dale, USA). The dialysates were collected at 60-min intervals into polyethylene tubes, immediately frozen and thawed before assaying for BE using a commercially available ELISA kit (IFA-S-1264, Peninsula Laboratories, San Carlos, USA). After the experiments, probe placement in the cingulate cortex (CC) and VTA was verified by sectioning frozen brains followed by analysis of cresyl violet stained slices.

\subsection{Drugs}

Loperamide (Sigma Aldrich), a MOR agonist, at a dose of $5 \mathrm{mg} / \mathrm{kg}$ and the MOR antagonist, naloxone methiodide (Sigma Aldrich), at a dose of $5 \mathrm{mg} / \mathrm{kg}$ of body weight in $0.25 \mathrm{ml}$ of distilled water were administered intragastrically using a special catheter $30 \mathrm{~min}$ before the experiments. The dose was chosen on the basis of our previous study as being most effective in behavioural experiments [17]. Control rats received $0.25 \mathrm{ml}$ of distilled water only.

\subsection{Statistical Analysis}

Data were analyzed by one-way analysis of variance (ANOVA) and Student-Newman-Keul's post hoc test.

\section{Results}

\subsection{Effect of Peripheral Treatment with MOR Ligands on the Binding Characteristics of MOR Receptors during Restraint Stress}

Our study showed that MOR affinity in the midbrain of rats subjected to restraint stress was higher than in naive animals (Table 1). By contrast, the number of these receptors in the frontal cortex of stressed rats reduced by half as compared to naive animals. 
Table 1. Effects of peripheral administration of loperamide (5 $\mathrm{mg} / \mathrm{kg}$ ) and naloxone methiodide $(5 \mathrm{mg} / \mathrm{kg}$ ) on the binding characteristics of $\mu$-opioid receptors in the midbrain and frontal cortex of stressed rats.

\begin{tabular}{|c|c|c|c|c|}
\hline \multirow[b]{2}{*}{ Animal Groups } & \multicolumn{2}{|c|}{ Midbrain } & \multicolumn{2}{|c|}{ Frontal cortex } \\
\hline & $\begin{array}{c}\mathrm{K}_{\mathrm{d}} \\
(\mathrm{nmol})\end{array}$ & $\begin{array}{c}\mathrm{B}_{\max } \\
\text { fmol/mg protein }\end{array}$ & $\begin{array}{c}\mathrm{K}_{\mathrm{d}} \\
(\mathrm{nmol})\end{array}$ & $\begin{array}{c}\mathrm{B}_{\max } \\
\text { fmol/mg protein }\end{array}$ \\
\hline $\begin{array}{l}\text { Control (water } \\
\text { only) }(\mathrm{n}=7)\end{array}$ & $7.2 \pm 1.9$ & $162 \pm 42$ & $5.0 \pm 1.3$ & $272 \pm 53$ \\
\hline $\begin{array}{l}\text { Water + stress } \\
\quad(\mathrm{n}=7)\end{array}$ & $12.1 \pm 2.1^{*}$ & $72 \pm 21$ & $10.0 \pm 1.9$ & $88 \pm 17^{*}$ \\
\hline $\begin{array}{l}\text { Loperamide only } \\
\qquad(\mathrm{n}=7)\end{array}$ & $4.2 \pm 0.7$ & $51 \pm 18^{*}$ & $3.7 \pm 0.4$ & $107 \pm 39^{*}$ \\
\hline $\begin{array}{l}\text { Naloxone } \\
\text { methiodide only } \\
\quad(\mathrm{n}=7)\end{array}$ & $3.9 \pm 0.8$ & $180 \pm 63$ & $6.1 \pm 1.1$ & $421 \pm 90^{*}$ \\
\hline $\begin{array}{c}\text { Loperamide }+ \\
\text { stress } \\
(\mathrm{n}=7)\end{array}$ & $6.7 \pm 1.9^{\#}$ & $158 \pm 30^{\#}$ & $7.5 \pm 0.5$ & $278 \pm 50^{\#}$ \\
\hline $\begin{array}{l}\text { Naloxone } \\
\text { methiodide }+ \\
\text { stress }(\mathrm{n}=7)\end{array}$ & $7.1 \pm 1.2^{\#}$ & $168 \pm 33$ & $6.6 \pm 1.1$ & $256 \pm 30^{\#}$ \\
\hline
\end{tabular}

Treatment with the MOR agonist loperamide at a single dose of $5 \mathrm{mg} / \mathrm{kg}$ was followed by a significant decrease in the density of MOR in both the midbrain and the frontal cortex of naive rats (Table 1). By contrast, the number of these receptors in the frontal cortex was shown to increase by more than 1.5 times after injection of the MOR antagonist naloxone methiodide at a single dose of 5 $\mathrm{mg} / \mathrm{kg}$ (Table 1). Thus, loperamide and methylnaloxone produced opposite effects on the density of MOR in the frontal cortex of non-stressed rats.

Loperamide was as potent as naloxone methiodide in preventing both an increase in the affinity and decrease in the density of MOR in the midbrain of stressed rats. Similar results were obtained in the frontal cortex of animals subjected to stress (Table 1).

\subsection{Effect of Peripheral Treatment with MOR Ligands on the Release of $\mathrm{BE}$ during Restraint Stress}

The mean basal concentration of $\mathrm{BE}$ in the perineuronal area of the CC and the VTA was $0.61 \pm 0.3$ and $1.58 \pm$ $1.16 \mathrm{pg} / \mu 1$, respectively (Figures 1(a) and (b)). Following a one-hour stress procedure a 2 -fold increase in the concentration of BE in the VTA of water-receiving animals (Figure 1(b)) was observed.

The MOR agonist loperamide slightly decreased the release of $\mathrm{BE}$ in the $\mathrm{CC}$ of water-receiving rats. However, the release of $\mathrm{BE}$ in the $\mathrm{CC}$ of non-stressed animals was elevated by 3 times after naloxone methiodide administration (Figure 1(a)). Both drugs did not modulate the

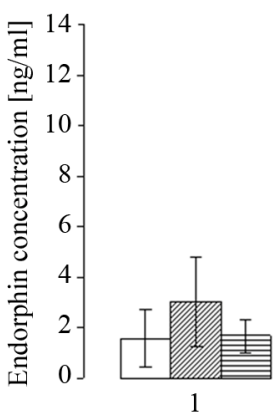

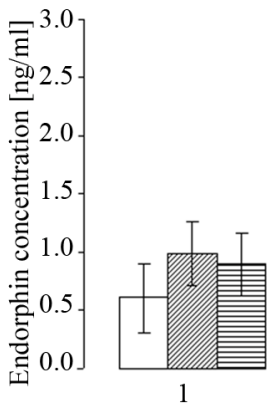

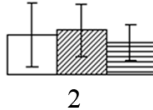

(a)
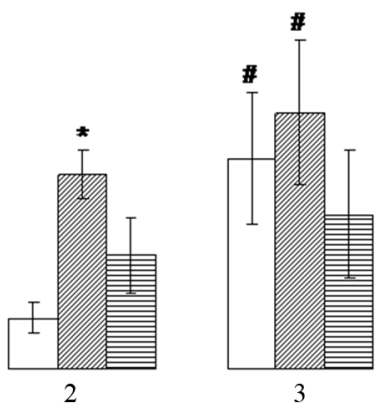

(b)

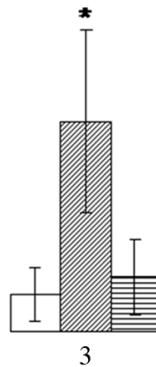

Figure 1. Effects of loperamide and naloxone methiodide on the release of $\beta$-endorphin (BE) in the VTA (a) and the CC of the brain (b) in naive and stressed rats. 1 -water, $n=6$; 2-loperamide, $5 \mathrm{mg} / \mathrm{kg}, \mathrm{n}=8$; 3-naloxone methiodide (5 $\mathrm{mg} / \mathrm{kg}), \mathbf{n}=8$. Drugs were administered intragastrically via a special catheter $30 \mathrm{~min}$ before the start of the experiments, n-the number of animals per group. Light bars, dialysate from non-stressed rats; slant shading, dialysate during stress; horizontal shading, dialysate after stress. Mean values S.E.M. *p $<0.05$ - significant differences as compared to rats of the same drug treatment group; ${ }^{\#} \mathbf{p}<0.05$ - significant differences as compared to corresponding water-receiving rats (i.e. 1).

release of this neuropeptide in the VTA of non-stressed specimens (Figure 1(b)).

Peripheral administration of both loperamide and naloxone methiodide significantly increased the extracellular level of BE in the CC of stressed rats (Figure 1(a)). Pretreatment with the MOR agonist loperamide abolished the stress-induced increase in the release of BE in the VTA of animals. However, the MOR antagonist naloxone methiodide significantly increased the release of the neuropeptide in the VTA before and during acute stress (Figure 1(b)).

\section{Discussion}

Our data suggest that the modulation in activity of peripheral MOR leads to changes in the activity of the central $\mu$-opioid system. The changes cause a modification of the characteristics of MOR and of release of BE in the cortex as well as in the midbrain of naive rats. Thus, the suppression of peripheral receptors by naloxone methio- 
dide led to an increase in the density of MOR in the cerebral cortex. Loperamide caused a significant reduction in the number of MOR in the cortex and in the midbrain. While pre-treatment with naloxone methiodide produced a pronounced increase in BE release in the $\mathrm{CC}$, administration of loperamide significantly decreased release of the neuropeptide in this brain structure.

It is known that restraint stress induces activation of the central opioid system [9]. Here we have shown that stress leads to an increase of MOR affinity in the midbrain, but decreased receptor density in the cerebral cortex. A dramatic increase of BE release in the VTA of the midbrain was observed under stress conditions. In contrast, only a slight elevation in the concentration of $\mathrm{BE}$ in the $\mathrm{CC}$ was obtained. These data indicated a critical role of the opioid system in the mechanisms of emotional stress in the midbrain. There has been convincing evidence that the release of BE in the VTA of the midbrain leads to a blockade of GABAergic transmission that has an inhibitory effect on dopamine-containing neurons that have processes in many brain structures of animals $[3,8$, 20]. Therefore, high concentrations of extracellular BE may cause stress-induced release of dopamine in various brain areas including the $\mathrm{CC}$, and the release of other monoamines in these regions is highly probable as well.

In the present study, we showed that both naloxone methiodide and loperamide produced an activation of opioid systems in the cerebral cortex during stress. However, in the VTA, loperamide suppressed stress-induced increase of $\mathrm{BE}$ release, whereas naloxone methiodide significantly enhanced neuropeptide release in this structure. It has been well established that loperamide, as well as naloxone methiodide, do not cross the $\mathrm{BBB}$ under normal conditions $[12,18]$. However, it is also possible that BBB permeability changes during stress [21,22] and naloxone methiodide as well as loperamide are able to cross the barrier in some brain structures. Future studies should focus on peripheral versus central drug effects in more detail.

\section{REFERENCES}

[1] M. J. Kreek, "Opioid Receptors: Some Perspectives from Early Studies of Their Role in Normal Physiology, Stress Responsivity, and in Specific Addictive Diseases," Neurochemical Research, Vol. 21, No. 11, 1996, pp. 14691488. doi:10.1007/BF02532387

[2] W. Wittmann, E. Schunk, I. Rosskothen, S. Gaburro, N. Singewald, H. Herzog and C. Schwarzer, "ProdynorphinDerived Peptides Are Critical Modulators of Anxiety and Regulate Neurochemistry and Corticosterone," Neuropsychopharmacology, Vol. 34, No. 3, 2009, pp. 775-785. doi:10.1038/npp.2008.142

[3] T. Esch and G. B. Stefano, "The Neurobiology of Stress Management," Neuro Endocrinology Letters, Vol. 31, No. 1, 2010, pp. 19-39.
[4] S. Ide, I. Sora, K. Ikeda, M. Minami, G. R. Uhl and K. Ishihara, "Reduced Emotional and Corticosterone Responses to Stress in Mu-Opioid Receptor Knockout Mice," Neuropharmacology, Vol. 58, No. 1, 2010, pp. 241-247. doi:10.1016/j.neuropharm.2009.07.005

[5] M. A. Wilson and L. Junor, "The Role of Amygdalar Mu-Opioid Receptors in Anxiety-Related Responses in Two Rat Models," Neuropsychopharmacology, Vol. 33, No. 12, 2008, pp. 2957-2968. doi:10.1038/sj.npp.1301675

[6] F. Lopez, L. G. Miller, M. L. Thompson, A. Schatzki, S. Chesley, D. J. Greenblatt and R. I. Shader, "Chronic Morphine Administration Augments Benzodiazepine Binding and GABAA Receptor Function," Psychopharmacology (Berl), Vol. 101, No. 4, 1990, pp. 545-549. doi:10.1007/BF02244235

[7] J. Le Merrer, B. Cagniard and P. Cazala, "Modulation of Anxiety by Mu-Opioid Receptors of the Lateral Septal Region in Mice," Pharmacology Biochemistry and Behavior, Vol. 83, No. 3, 2006, pp. 465-479. doi:10.1016/j.pbb.2006.03.008

[8] A. Rezayof, S. S. Hosseini and M. R. Zarrindast, "Effects of Morphine on Rat Behaviour in the Elevated Plus Maze: The Role of Central Amygdala Dopamine Receptors," Behavioural Brain Research, Vol. 202, No. 2, 2009, pp. 171-178. doi:10.1016/j.bbr.2009.03.030

[9] P. Zeman, M. Alexandrová and R. Kvetnansky, “Opioid $\mathrm{Mu}$ and Delta and Dopamine Receptor Number Changes in Rat Striatum during Stress," Endocrinologia Experimentalis, Vol. 22 No. 1, 1988, pp. 59-66.

[10] I. Liberzon, S. F. Taylor, K. L. Phan, J. C. Britton, L. M. Fig, J. A. Bueller, R. A. Koeppe and J. K. Zubieta, "Altered Central Micro-Opioid Receptor Binding after Psychological Trauma," Biological Psychiatry, Vol. 61, No. 9, 2007, pp. 1030-1038. doi:10.1016/i.biopsych.2006.06.021

[11] G. F. Koob, H. O. Pettit, A. Ettenberg and F. E. Bloom, "Effects of Opiate Antagonists and Their Quaternary Derivatives on Heroin Self-Administration in the Rat," Journal of Pharmacology and Experimental Therapeutics, Vol. 229, No. 2, 1984, pp. 481-486.

[12] R. D. Egleton, T. J. Abbruscato, S. A. Thomas and T. P. Davis, "Transport of Opioid Peptides into the Central Nervous System," Journal of Pharmaceutical \& Science, Vol. 87, No. 11, 1998, pp. 1433-1439. doi: $10.1021 /$ js $980062 \mathrm{~b}$

[13] K. Shinoda, V. J. Hruby and F. Porreca, "Antihyperalgesic Effects of Loperamide in a Model of Rat Neuropathic Pain Are Mediated by Peripheral Delta-Opioid Receptors," Neuroscience Letters, Vol. 411, No. 2, 2007, pp. 143-146. doi:10.1016/j.neulet.2006.10.027

[14] S. K. Sudakov, I. V. Rusakova, M. M. Trigub and I. A. Pomytkin, "Methylnaloxone Suppresses the Development of Withdrawal Syndrome in Morphine-Dependent Rats," Bulletin of Experimental Biology and Medicine, Vol. 143, No. 5, 2007, pp. 608-610. doi:10.1007/s10517-007-0194-8

[15] S. K. Sudakov, S. V. Sotnikov, N. Yu. Chekmareva, A. A. Kolpakov, Yu. A. Chumakova and A. E. Umryukhin, "Changes in $\beta$-Endorphin Level in the Cingulate Cortex 
in Rats after Peripheral Loperamide and Methylnaloxone Administration at Rest and during Emotional Stress," Bulletin of Experimental Biology and Medicine, Vol. 149, No. 2, 2010, pp. 167-169. doi:10.1007/s10517-010-0898-z

[16] S. K. Sudakov and M. M. Trigub, "Hypothesis on Reciprocal Interactions between the Central and Peripheral Components of the Endogenous Opioid System," Bulletin of Experimental Biology and Medicine, Vol. 146, No. 6, 2008, pp. 663-666. doi:10.1007/s10517-009-0368-7

[17] S. K. Sudakov, V. G. Bashkatova, A. A. Kolpakov and M. M. Trigub, "Peripheral Administration of Loperamide and Methylnaloxone Decreases the Degree of Anxiety in Rats," Bulletin of Experimental Biology and Medicine, Vol. 149, No. 3, 2010, pp. 273-275. doi:10.1007/s10517-010-0925-0

[18] H. Fischer, R. Gottschlich and A. Seelig, "Blood-Brain Barrier Permeation: Molecular Parameters Governing Passive Diffusion," Journal of Membrane Biology, Vol. 65, No. 3, 1998, pp. 201-211. doi:10.1007/s002329900434
[19] G. Paxinos and C. Watson, "The Rat Brain in Stereotaxic Coordinates,” Academic Press, New York, 1982, p. 474.

[20] S. R. Wachtel and F. J. White, "Electrophysiological Effects of BMY 14802, a New Potential Antipsychotic Drug, on Midbrain Dopamine Neurons in the Rat: Acute and Chronic Studies," Journal of Pharmacology and Experimental Therapeutics, Vol. 244, No. 1, 1988, pp. 410416.

[21] H. S. Sharma and S. F. Ali, "Alterations in Blood-Brain Barrier Function by Morphine and Methamphetamine," Annals of the New York Academy of Sciences, Vol. 1074, 2006, pp. 198-224. doi:10.1196/annals.1369.020

[22] J. J. Lochhead, G. McCaffrey, C. E. Quigley, J. Finch, K. M. Demarco, N. Nametz and T. P. Davis, "Oxidative Stress Increases Blood-Brain Barrier Permeability and Induces Alterations in Occludin during Hypoxia-Reoxygenation," Journal of Cerebral Blood Flow \& Metabolism, Vol. 30, No. 9, 2010, pp. 1625-1636. doi:10.1038/jcbfm.2010.29 